\title{
Effects of Gorkha earthquake: corporate staff's psychological well-being and perceived organizational support at Kathmandu valley on the aftermath of earthquake in Nepal
}

\section{Abstract}

Background: Gorkha Earthquake 2015, had traumatized the Nepali people. Staff from the corporate sector were equally impacted. ${ }^{1}$ Prevalence of uncertainty, fear and psychological distress are a common phenomenon of any disaster situations, ${ }^{2}$ which was observed increased at workplaces and residences of the public during and the aftermath of the mega-earthquake. Systematic psychological support and policy level interventions were a challenge to address such unexpected needs. ${ }^{3}$ A study on the psychological well-being and perceived support were inevitable to address the problems.

Aim: To examine the psychological well-being and perceived organizational support of the staff of corporate sector in Nepal.

Methods: A non-experimental, survey study model was used to explore the psychological distresses (Anxiety, Depression and Psychosomatic) and perceived support from their institution through using self-rated online survey. HSCL-25, BSI and a locally prepared Likert scale for the perceived support were applied to the corporate staff. Descriptive statistical analysis of the study was extracted from the SPSS.

Results: The Anxiety scores of $19.3 \%(\mathrm{~N}=57)$ respondents were found to be higher than the threshold. The depression and psychosomatic assessment revealed, $3.5 \%$ of the respondents were above than the cut off scores, and $1.75 \%$ was found to be in need of suicidal care immediately. $76 \%$ respondents perceived, their managers and institutions took measures for the reduction of
Volume 7 Issue 2 - 2018

Adhikari Yubaraj
Mental Health Psychologist, University of Liverpool, UK

Correspondence: Yubaraj Adhikari, Mental Health Psychologist, University of Liverpool, UK, Email yadhikari@gmail.com

Received: August 09, 2016 | Published: April 06, 2018

distresses and equally found hopeful for the support in future disasters too.

Conclusion: The study revealed, a one-fifth numbers of staff were found to be affected by the distresses in post-earthquake situations. The institutions and managers of corporate sectors have to develop policies and provisionary support to reduce the risk of burnout and effect of mental health into their workforces. The respondents were found optimistic in addressing their challenges in future disaster situations.

Keywords: Nepal earthquake, psychological distress, disaster response, care of staff, corporate staff management

\section{Introduction}

On 25th April 2015, at 11:56 local time, a massive 7.9 Richter scale earthquake struck Nepal, with the epicentre in Gorkha District (north-west) of Kathmandu and south of the China border. More than 100 aftershocks followed. The strongest aftershock, measuring 7.3 magnitudes, struck on 12 May at 12:50 local time. According to the government, 32 districts have been affected by the latest quake, including those still recovering from the 25 April earthquake. The epicentre of the main shock is approximately $34 \mathrm{~km}(21 \mathrm{mi})$ eastsoutheast of Lamjung, Nepal, and its hypocentre at a depth of approximately $15 \mathrm{~km}(9.3 \mathrm{mi})$. It is the most powerful disaster to strike Nepal since the 1934 Nepal-Bihar earthquake. These areas are densely populated; including remote villages perched on hilly areas. ${ }^{1}$ The earthquake, not only devastated lives and livelihood of the general population, but equally impacted economic institutions and its staff. ${ }^{4}$ Hundreds of tremors and aftershocks became usual, where public perception of insecurity, uncertainty and constant fear remained and still exists. Corporate sector and its service providers repeatedly faced dilemma to open the services for general public and also ensuring the safety and security of their staff. Staff members also had uncertainty and insecurity to provide better care to the families and dependent and joining back the office immediately in the aftermath of the earthquake. ${ }^{4}$ Many staff whose relatives were outside of the earthquake affected areas has faced tremendous pressure to leave Kathmandu and join their family. Some employees lost their loved ones and property not only limited to Kathmandu valley but also in surrounding districts of Kathmandu valley. Human Resources Society Nepal (HRSN) realized the constant fear and uncertainty among their colleagues and organized an orientation on 'psychological impact of the earthquake and its effect on the human resource in Nepal' on May 29, 2015. The orientation session was also used to understand the common psychological distresses faced by the staff members and their families through a discussion. HRSN envisioned to survey 'Survey on psychological well-being and perceived organizational support in the aftermath of Nepal Earthquake' and facilitated the process. This survey aimed to review the following objectives and brought a dialogue for a policy review to address the ongoing the psychological challenges faced by the staff members during its fourth general assembly. The outcomes of this research equally worked to lobby for possible measures to be taken for future potential crisis situations not only limited to the earthquake but equally be applied to other crisis situations.

\section{Research objective}

The study aimed at understanding the following objectives:

i. To measure existing psychological distresses of professionals working for corporate sectors immediately after the crisis.

ii. To explore perceived support of respective institutions during and after the crisis event. 
iii. To outline possible measures that can be adhered by the HR managers and agencies to support better the staff and motivate through quality care.

\section{Research methods}

\section{Research design}

The Study followed a non-experimental and non-comparative cross-sectional study design to measure the psychological distress and perceived institutional support in the aftermath of the mega earthquake in Nepal. The cross-sectional study design was a suitable approach to understand the prevalence of any psychological problem in a given time. ${ }^{5,6}$ emphasized a cross-section design is a fast and resource friendly process to explore and examine any psychological challenges in a limited period. An alternative approach would have been to carry out a longitudinal and comparative study design, which is often a longer-term and resources demanding research and exposes the respondents to potential risks due to multiple engagements. Additionally, it helped the researcher to quickly disseminate the prevalence of the psychological challenges to the institutions and managers to take measures in addressing the problem before developing a prolonged mental health problem to their staff members. Therefore, a survey design was deemed a viable solution and selected to apply in this research.

\section{Research population and sampling}

The study covered the Kathmandu valley. There was no exact statistics available on how many people are employed in the corporate sector's staffing in Kathmandu Valley. As per a 2014 report, 17\% of 2.14 million workforces are involved in the non-agricultural service sectors, which signifies, about four hundred of thousands staff are engaged in the corporate industry (ILO, 2014). Over $50 \%$ of the staff of corporate sectors are based in Kathmandu valley. Therefore the estimated population size came from a hundred thousand people. After using the $90 \%$ confidence interval for an unknown population with $10 \%$ of margin of error and $50 \%$ response distribution, the total sample size was determined as 68 respondents. ${ }^{8}$

\section{Data collection tool}

HSCL-25, with 25 items, covers the symptoms of anxiety and depression. Initial, ten items of the scale capture the symptoms of anxiety disorder, whereas, additional fifteen-items are for the measurement of depression. ${ }^{9}$ The four-point Likert scale follows, "Not at all," "A little," "Quite a bit," "Extremely," and rated 1-4 respectively. Cronbach $\alpha$ of HSCL-25 was measured between 0.84 to 0.87 , where the internal consistency was studied high for this tool. ${ }^{10}$, Thapa et al. ${ }^{11}$ validated into the Nepali population, and the results showed Cronbach $\alpha$ in both the measures were 0.89 and 1.75 was found as a cut-off score. The seven-items to measure physically unexplained body pain (psycho-somatic) was validated and used earlier in Nepal by Emmelkamp et al. ${ }^{12}$ with good internal consistency and reliability score of 0.9 for the BSI. The researcher also used the HSCL and BSI in Nepali population for over a half decade with the conflict victim population $(\mathrm{n}=1442)$ as a longitudinal monitoring tool for the therapeutic support group members. HSCL-25 and BSI were found consistent across the various age, geography, language and sex of the of the Nepali population (ICRC, 2016). ${ }^{13}$ Baird et al. ${ }^{14}$ again validated the HSCL-25 for Nepali speaking Bhutanese community. Perceived institutional support scale, a locally made five items by the researcher, in four-point Likert scale presented in Chart 1, was piloted with 30 participants before the sharing with the respondents. The face validity and internal consistency were strengthened and ensured before the administration. Lastly, the respondents were requested to provide three recommendations to each human resources managers and their employer institutions.

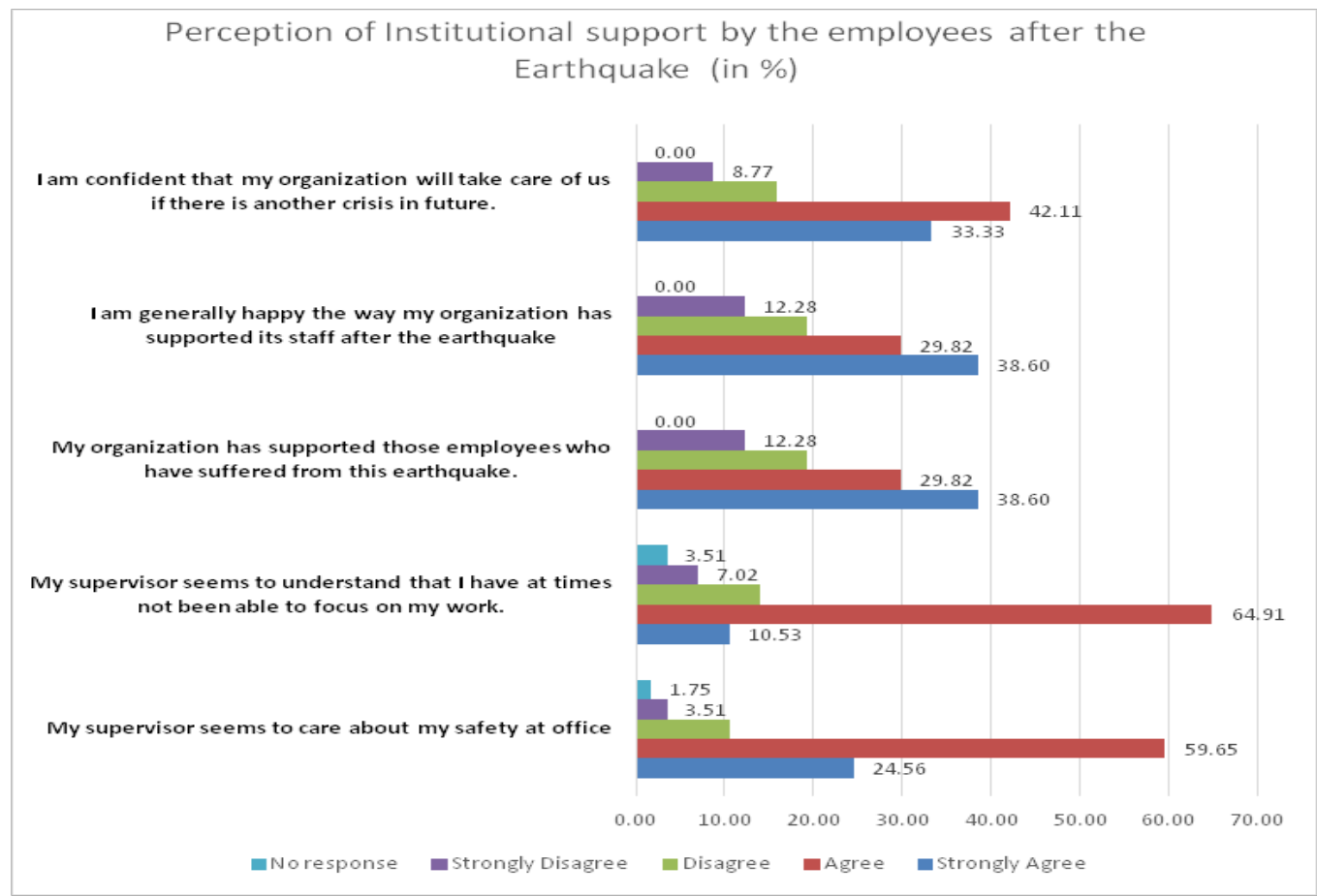

Chart I Perception of support of HR managers and Institutions by the employees after the Earthquake in \%. 


\section{Data collection process}

A non-random sampling method was chosen to collect the data. The respondents who were not the staff of the private sectors and not residing in the Kathmandu Valley in the aftermath of Earthquake were excluded from the study. The data collection tools in Nepali version were piloted to 30 individuals before the implementation. Feedbacks from the pilot phase were incorporated before administrating the tool for samples. Electronic distribution (Google docs) of data collection tool to the Human Resources (HR) Managers, i.e. members of Human Resources Society Nepal was done. HR Managers sent the Google doc version to one-hundred staff members through the individual email. The tool primarily outlined on the objective of research, vital information on how to fill up the form, confidentiality, anonymity and consent to the use of collected data. Declaration of no conflict of interest and outcomes may consistently use only for academic and policy advocacy were clarified in advance.

\section{Data cleaning and analysis}

The time of data collection was three months after the mega earthquake, however aftershocks on a daily basis were persisted even during the period. The process took two weeks to complete the process. The research team managed to retrieve sixty-three forms answered, with a $63 \%$ of response rate, by the respondents. Four out of them were not properly filled out, whereas, fifty-seven respondents information with little or no missing data were retained for the analysis purpose. Data were coded, and numbering was given before the entry in Excel and statistical package for the social sciences (SPSS). Few missing data for one or two items were provisioned to be filled by mean value out of answered questions. Excel was used to calculate the demographic information and perceived institutional support. Distress related data collected by using HSCL-25 and BSI scale were analyzed in SPSS. The descriptive statistics with mean, median, mode and percentage of the respondents above the cut off scores were derived. The mean values in comparison with the socio-demographic clusters of the respondents are presented in the results section. Key feedback to the HR managers and institutions were taken using content analysis and repeated key terms.

\section{Results of the survey}

\section{Demography and socio-economic variables}

Out of 57 respondents, $67 \%$ of the respondent were male. The gender distribution across all positions was proportional; however, not a single female was found in senior executives (14 out of 57 were all men). $87 \%$ respondent was below 39 years, which shows the workforce is overwhelmed by the young and energetic age group people. Only one percent respondent was over fifty years of age. Ethnic inclusion and diversity were also analyzed. Over eighty percent of the respondents were either from Brahmin (47\%) or Newar (33\%) social strata. Chetteris were the third shared $14 \%$ of inclusion, whereas, $5 \%$ inclusion from Terai higher caste group found. Composition and diversity of workforce to ethnic nationalities, minorities and Dalits was yet to be seen. The educational qualification of respondents was predominated by the Master's Degree holders ( $83 \%$ ), whereas, above master's degree qualification was twelve percent participation. Only five percent came from Bachelor's degree background. Most of the Bachelor's degree holders were from below 30 years of age group; except one respondent who crossed that age bar (Chart 2), (Chart 3).

The overall workforce who participated in this survey were highly educated individuals. The level of position in their respective institutions was also represented highly in the survey. 68.5\% respondents were either middle managers $(44 \%)$ or senior managers (24\%); followed by supervisory and support level. Average salary and enumeration were also analyzed, the average salary range of male participants was found higher compared with the female; which might be caused by the lesser inclusion of female in most top executives. More than fifty percent (54\%) of the respondent reported five years or above experiences in their respective field. The majority of the respondent, above $63 \%$, comes from more than 40,000 per month income group. The analysis has shown that the qualification and years of experience were highly correlated with their income and designation in their respective field; that not only promotes their psychological wellbeing but also prevents from being boredom at work and reduces burnout (Chart 4), (Chart 5).

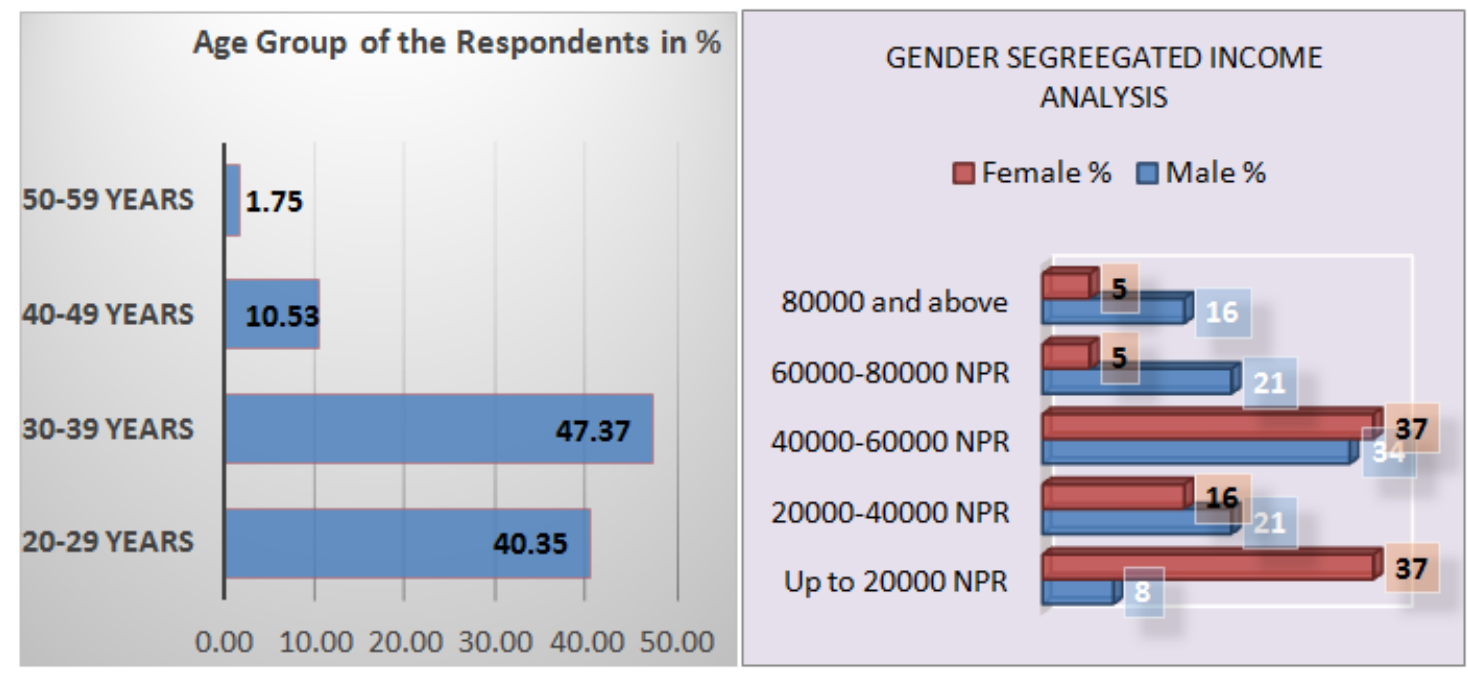

Chart 2 Age group of respondent.

Chart 3 Gender segregated income. 


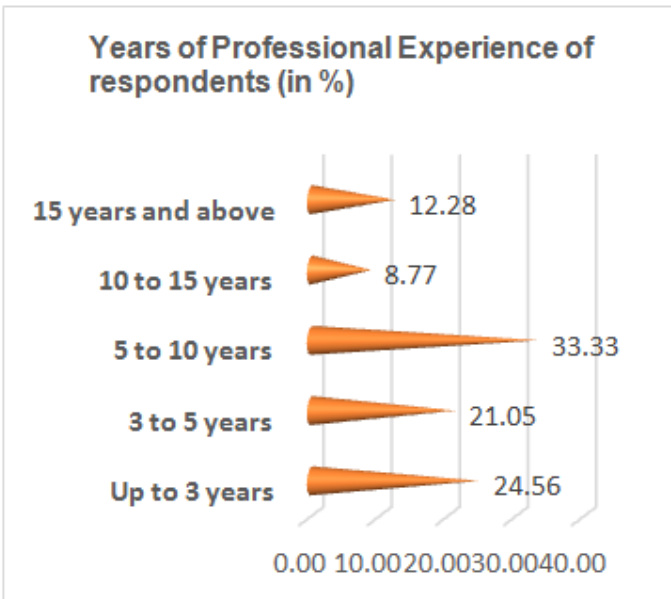

Chart 4 Years of experiences of the respondent.

\section{Psychological distresses three months of the mega- earthquake}

The distresses of respondent were analyzed after considering different elements of the respondents. At the individual level, the anxiety level of $19.3 \%$ respondent was found higher than the threshold, whereas, overall distress, level of depression and level of psychosomatic pain was above the threshold for $3.5 \%$ of respondent. $1.75 \%$ participants need further assessment of potential suicidal risk (Chart 6). Gender-segregated data outcomes have shown significant differences between the mean distress of men and women. Overall distress of male (Mean=14.46) was found lower than the mean value of overall distress (Standard Mean $=15.01$ ) of the participants; whereas female participants (Mean=15.70) were more distressed than male (Chart 7). Distresses of Support level (Mean: 19.0), and senior

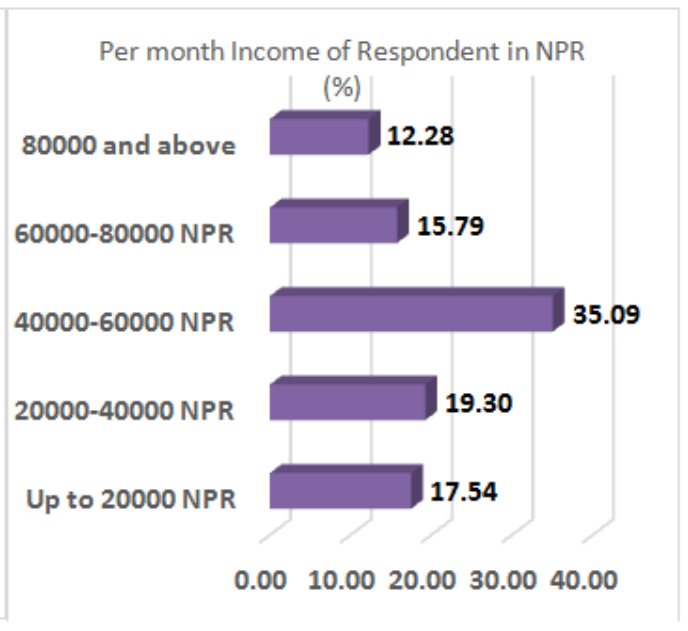

Chart 5 Average salary grid of the respondent.

managers (Mean: 16.98) was found higher than others (Standard Mean: 15.01); middle managers were comparatively more resilient (Mean: 13.76) (Chart 8), (Chart 9).

Mean distress of respondent with above post-graduation degree shown extremely high $($ Mean=22.48), where, distresses of post graduated (Mean: 14.93) respondent was even slightly below the standard mean. Distress of respondent with Bachelor's degree has relatively too low (Mean=12.42) than the Standard Mean. Two age groups; 20-29 years of age group (Mean=16.02) and 40-49 years of old age group (Mean=16.56) were found relatively more distressed than compared two other age groups (Standard Mean: 15.01). Females from 30-39 years of old age group were highly anxious; as compared with the males from 20-29 years of old age group.

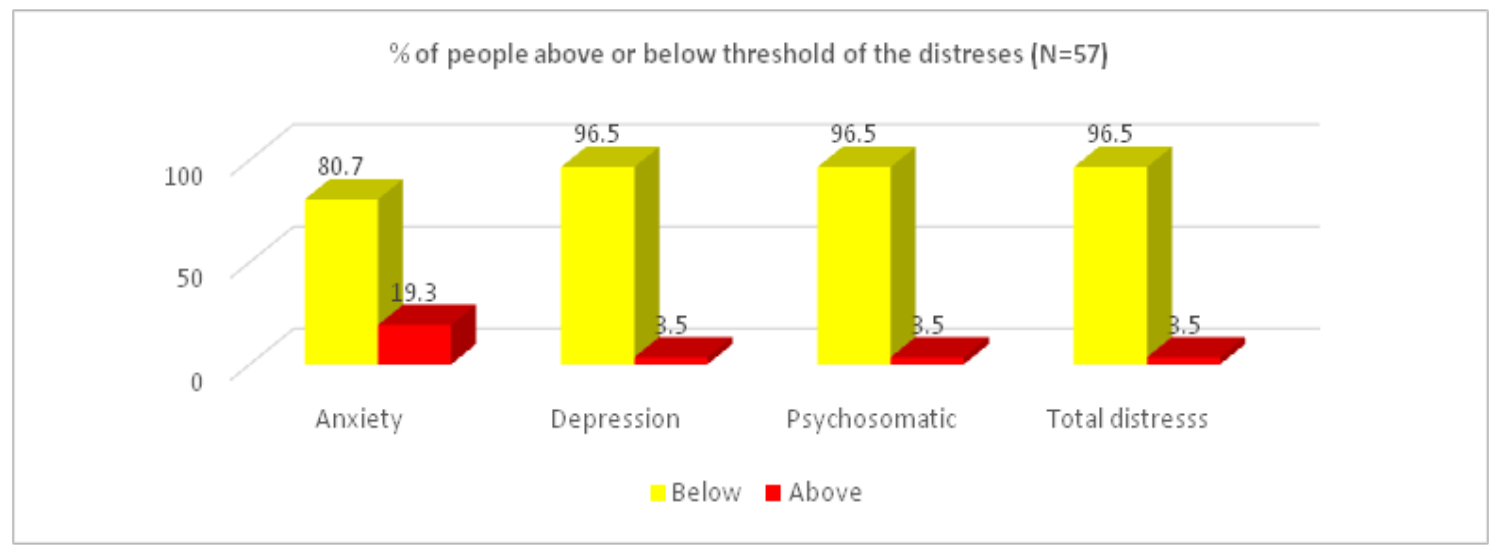

Chart 6 Overall distress of the respondents segregated on below and above the threshold.

Respondents from Terai origin (Mean: 21.67) were found heavily distressed, followed by Bramhin (Mean: 16.49); whereas distressed of Cheetri (Mean: 9.82) respondent was sharply low than the standard mean (Mean: 15.01) (Chart 10).

\section{Perceived support from the HR managers and institutions}

The respondents' rating towards their institution and HR manager was very impressive. $69 \%$ respondents have shown overall satisfaction 
and were categorized their perceived level of support under 'strongly agree' and 'agree' categories in all five domains. Nearly $70 \%$ respondent was found happy and satisfied with the support available to them through their HR managers and respective institutions after the mega earthquake. $76 \%$ respondent reported that their HR managers were very concerned with the stress of their subordinate faced and did not push a lot of institutional priorities. $85 \%$ of respondent Perceived that their HR managers as caring and supportive. The majority of those who disagree (average of $21 \%$ respondents) came from the corporate house and insurance sectors; and who were mid-managers and in lower positions (equally male and female). Nevertheless, 75\% respondent believed that their institution would support them in the future crisis like the mega earthquake in April 2015 (Chart 1).

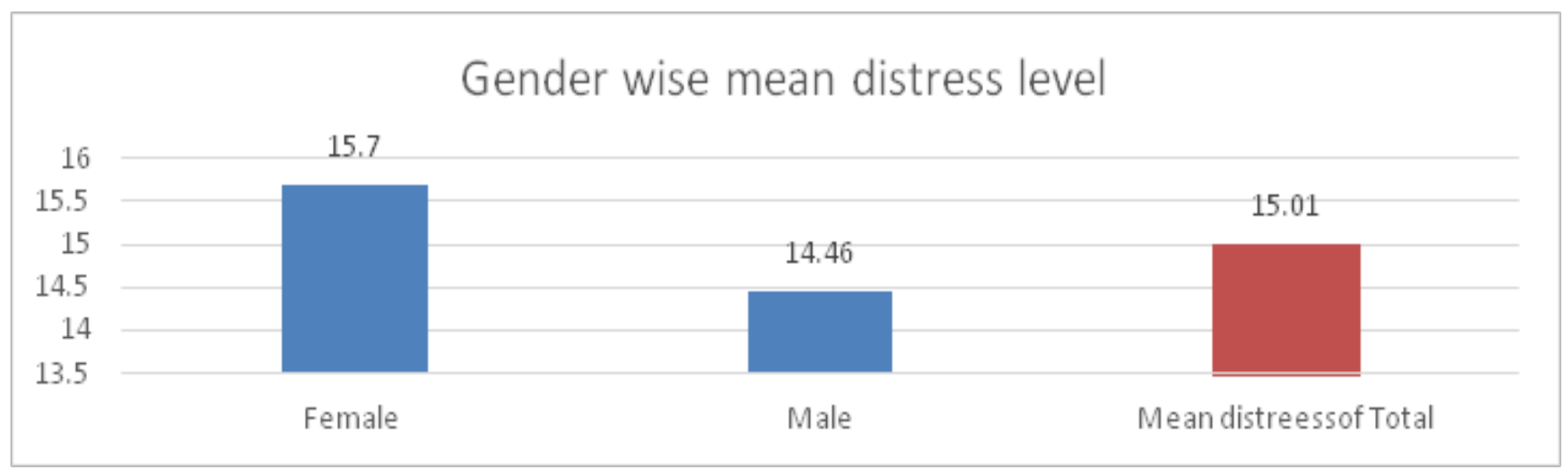

Chart 7 Gender-segregated mean distress of male and female.

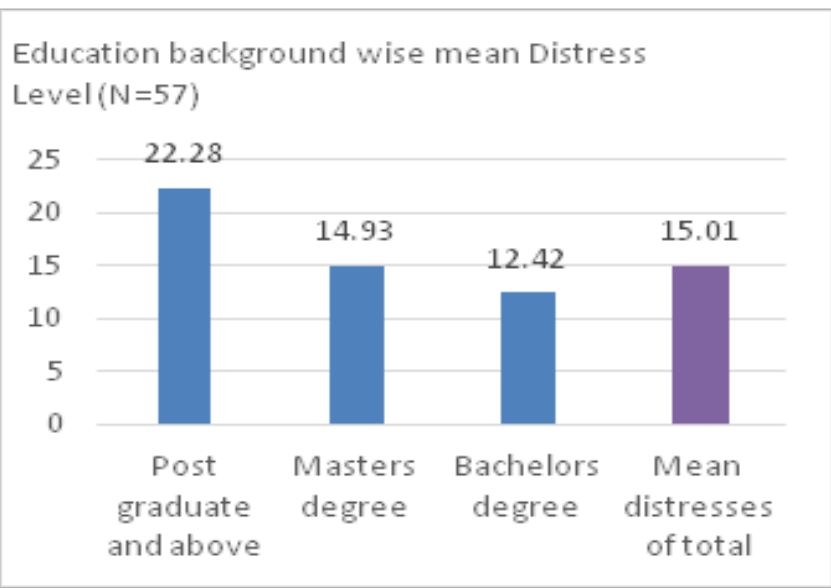

Chart 8 Qualification wise mean distress.

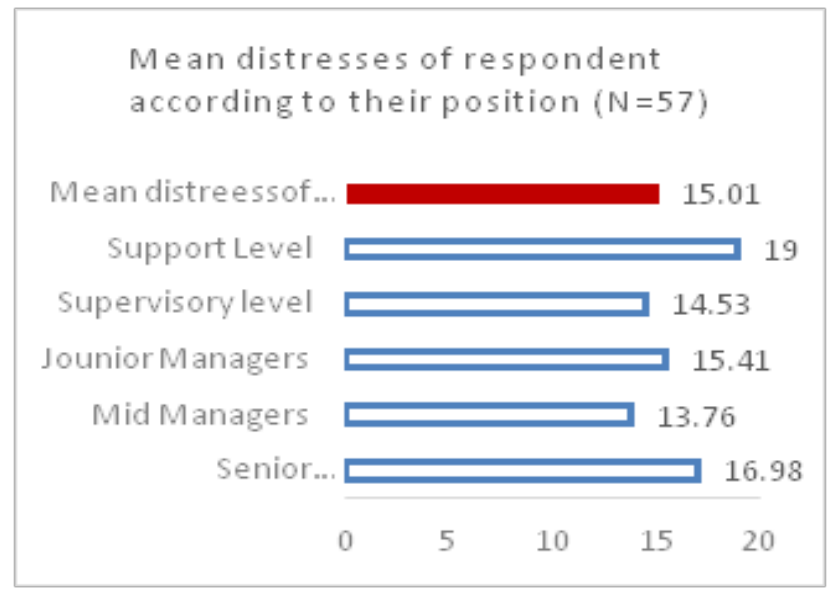

Chart 9 Position (designation) wise mean distress.

\begin{tabular}{|c|c|c|c|c|c|}
\hline \multicolumn{6}{|c|}{ Ethnicity wise mean level of distress $(N=57)$} \\
\hline 23 & & & & 21.67 & \\
\hline & 16.49 & & \multirow[b]{2}{*}{14.04} & & \multirow{2}{*}{15.01} \\
\hline 15 & & & & & \\
\hline 10 & & 9.82 & & & \\
\hline 5 & & & & & \\
\hline 0 & Bramhin & Cheetri & Newar & Terai origion & Meanvalue of distress \\
\hline
\end{tabular}

Chart 10 Ethnicity wise mean distress. 


\section{Discussion}

The corporate sector has not only an enormous potential but equally the best interest to support the people affected by any disaster situations. ${ }^{15}$ Either it is in Hurricane Catrina and Rita ${ }^{16}$ or any other disaster situations, ${ }^{17}$ the private sector is equally affected. The psychological and emotional aspect of the impact of such calamities is relatively less studied even in industrialised contexts, where Nepal indeed have a rare and limited understanding on such issues. This study explored an opportunity to understand the humanitarian aspects of impact on the personnel of the private sector and the availability of perceived support. Despite the high ratings on the perceived support, the prevalence of anxiety in one out of five corporate sectors (19.3\%) followed by $4 \%$ of depression prevalence with $4 \%$ of suicidal ideation outlines that significant strata of the staff were affected. The study findings are in line with the increased level of anxiety, depression and suicide among the general population after the earthquake in Nepal. ${ }^{18,19}$ As Collins et al. ${ }^{20}$ suggested, there is a link of socio-economic and geographic situations to cope with the unexpected calamities in life, the staff from lower hierarchy with little or low experiences, staff from outside of the Kathmandu valley (mainly from Terai ethnic) and female hopefully with small children were found highly affected. A two-year long longitudinal study after the Great East Japan Earthquake and tsunami in Japan in 2011 study explored that women, elderly and people with the destruction of the houses were among the ones with a higher level of persistent distress, whereas the alcoholism in male was drastically increased. ${ }^{21}$ The study outcomes suggest a clear hierarchical, gender and geographical factors as vulnerabilities of the increased stress.

Not surprisingly, staff with highest income group and top most in the hierarchy were also found with increased stress; which signifies the association of increased stress in high monthly income group especially in an urban population of Nepal. ${ }^{22}$ The conforming factors associated with such results could not be explored, however, increased uncertainty and fear of possible shrink on profit, the risk of lesser job opportunities, and increased family and official workload might be the cause of the high distresses. Galea et al. ${ }^{2}$ explored the higher chances of PTSD not only with the general people and children but equally to the workers and personnel working after the human-made or natural disaster situations. The distresses and PTSD may prologue, a high level of symptoms of the PTSD (22\% of respondent, $n=157$ Greek survivors of the 1999 earthquake) was persisted even after four years of the earthquake. This study is relatively the first in Nepali context, which could not compare with other reviews in the same context. However, the increased anxiety and prevalence of depression with rigorous ideation of suicide on a significant percentage of the studied population outlines for precautionary measures to be taken for the future calamities..$^{23,24}$

\section{Limitations of the study}

This study is a cross-sectional design; there was no baseline, which did not allow a comparative analysis of the distress across the timeframe. The study only includes a random distress analysis; where as stress factors related to work, family, and specifically induced by the earthquake specific were not segregated; which need extensive research after using qualitative and quantitative methods. The sample size of this study was relatively small, the generalization and replicability of findings are very limited. A representative sample of the workforce could not maintain a minimum of over 350 would have been an ideal. ${ }^{8}$ Individual biases, as some respondents themselves were HR managers, might tend to rate over the perceived support. A culture of confirmation to the hierarchy might have influenced the results. Therefore, the findings of this study should be interpreted while looking with such caveats in mind.

\section{Future research perspectives}

The psychosocial well-being of staff and care practices of the corporate sector is a new field; therefore an extensive and institutionally mandatory research on their well being may lead to the improvement of working efficiency of the workforce and equally gives an added value to the recruiters that they provide the best care to their employees. Perception of institutions, executives and HR managers towards their staff is essential to invest because an ultimate goal of human resources department is not only to recruit the outstanding staff but equally facilitate the services that they remain a well-functioning working force to generate the revenue and to prevent burnouts and change of companies. A longitudinal study with a certain level of intervention or a controlled survey of perceived support and scale of distresses after establishing a certain level of psychological and mental health support. Emotional intelligence and dispute (conflict) management area among the workforce also reduces psychological challenges, work-induced stresses and prevents burn out. ${ }^{25}$ Institutional support to develop such skills can be perceived as preparedness of workforces before the disasters. ${ }^{26,27}$ Desk review of human resource policies and identify the gaps where there the recommendation of this study may be endorsed at a certain level. Whereas, development of contingency planning, implementation of the plan and evaluation on the implementation of such plans are also envisioned ${ }^{23}$ for the business continuity after mega-disasters.

\section{Conflict of interest}

None.

\section{Acknowledgement}

Author would like to provide gratitude to HRSN executive members especially Mr Amit Sharma and Mr Tanka Bhattrai for their invaluable support in the course of this process.

\section{Disclaimer}

The author heartily welcomes any feedback at yadhikari@gmail. com

\section{References}

1. National Planning Commission, NPC. Nepal Earthquake 2015 Post Disaster Needs Assessment. Vol. A: Key Findings. Kathmandu, Nepal. 2015.

2. Galea S, Nandi A, Vlahov D. The epidemiology of post-traumatic stress disorder after disasters. Epidemiol Rev. 2005;27(1):78-91.

3. Carpenter S, Grünewald F. Disaster preparedness in a complex urban system: the case of Kathmandu Valley, Nepal. Disasters. 2015;1-21.

4. Nepal Economic Forum, NEF. Economic impact of Earthquake; 2015.

5. De Vaus DA, de Vaus D. Research design in social research. London, UK: Sage Publications. 2001 
6. Carlson MD, Morrison RS. Study design, precision, and validity in observational studies. J Palliat Med. 2009;12(1):77-82.

7. Caruana EJ, Roman M, Hernández-Sánchez J, et al. Longitudinal studies. J Thorac Dis. 2015;7(11):E537-540.

8. Cohen J. A power primer. Psychol Bull.1992;112(1):155-159.

9. Van Ommeren M, Sharma B, Thapa S, et al. Preparing instruments for transcultural research: use of the translation monitoring form with Nepali-speaking Bhutanese refugees. Transcultural Psychiatry. 1999;36(3):285-301.

10. Derogatis LR, Lipman RS, Rickels K, et al. The Hopkins Symptom Checklist (HSCL): A self-report symptom inventory. Behav Sci. 1974;19(1):1-15.

11. Thapa SB, Hauff E. Psychological distress among displaced persons during an armed conflict in Nepal. Soc Psychiatry Psychiatr Epidemiol. 2005;40(8):672-679.

12. Emmelkamp J, Komproe IH, Van Ommeren M, et al. The relation between coping, social support and psychological and somatic symptoms among torture survivors in Nepal. Psychol Med. 2002;32(08):1465-1470.

13. ICRC. Hateymalo accompaniment programme: ICRC's comprehensive psychosocial support programme to the families of missing persons in Nepal (2010-2016). 2016.

14. Baird MB, LeMaster JW, Harding A. Translation and cultural adaptation of the Hopkins Symptom Checklist-25 (HSCL-25) into Nepalese for use with Bhutanese refugees. Online Journal of Cultural Competence in Nursing and Healthcare. 2016;6(1):14-30.

15. Sayegh T. Corporate involvement in disaster response and recovery: an analysis of the Gujarat Earthquake (Doctoral dissertation, Massachusetts Institute of Technology). 2004

16. Bonnie Rogers, Elizabeth Lawhorn MSN. Disaster preparedness: occupational and environmental health professionals' response to Hurricanes Katrina and Rita. Workplace Health \& Safety. 2007;55(5):197207.
17. Ritchie BW. Chaos, crises and disasters: a strategic approach to crisis management in the tourism industry. Tourism Management. 2004;25(6):669-683.

18. Simkhada P, van Teijlingen E, Pant PR, et al. Public health, prevention and health promotion in post-earthquake Nepal. Nepal $J$ Epidemiol. 2015;5(2):462-464.

19. Cousins S. Nepal's silent epidemic of suicide. Lancet. 2016;387(10013):16-17.

20. Collins S, Long A. Too tired to care? The psychological effects of working with trauma. J Psychiatr Ment Health Nurs 2003;10(1):17-27.

21. Kanehara A, Ando S, Araki T, et al. Trends in psychological distress and alcoholism after The Great East Japan Earthquake of 2011. SSMPopulation Health. 2016;2:807-812.

22. Niraula K, Kohrt BA, Flora MS, et al. Prevalence of depression and associated risk factors among persons with type-2 diabetes mellitus without a prior psychiatric history: a cross-sectional study in clinical settings in urban Nepal. BMC Psychiatry. 2013;13:309.

23. Paton D. Disaster business continuity: promoting staff capability. Disaster Prevention and Management: An International Journal. 1999;8(2):127133.

24. Livanou M, Kasvikis Y, Başoğlu M, et al. Earthquake-related psychological distress and associated factors 4 years after the Parnitha earthquake in Greece. European Psychiatry. 2205;20(2):137-144.

25. Cieslak R, Shoji K, Douglas A, et al. A meta-analysis of the relationship between job burnout and secondary traumatic stress among workers with indirect exposure to trauma. Psychol Serv. 2014;11(1):75-86.

26. Bonanno GA, Galea S, Bucciarelli A, et al. What predicts psychologica resilience after disaster? The role of demographics, resources, and life stress. J Consult Clin Psychol. 2007;75(5):671- 682.

27. International Labour Organisation. Nepal Labour Market. 2014. 